\title{
Molecular and morphological evidence for hybridization between two ecologically distinct grasshoppers (Melanoplus sanguinipes and $M$. devastator) in California
}

\author{
MATTHEW R. ORR, ADAM H. PORTER $\dagger$, TIMOTHY A. MOUSSEAU $¥$ \& \\ HUGH DINGLE* \\ Department of Entomology, University of California, Davis, CA 95616, †Department of Biological Sciences, Bowling \\ Green State University, Bowling Green, $\mathrm{OH} 43403$ and $\ddagger$ Department of Biological Sciences, University of South
}

Carolina, Columbia, SC 29208, U.S.A.

\begin{abstract}
This paper applies the biological species concept to two ecologically distinct species of grasshopper, Melanoplus sanguinipes and $M$. devastator, by testing for reproductive isolation in the field in California. Two independent techniques for assessing gene flow between species were employed. Firstly, we examined male genitalic morphology in populations from the foothills of the Sierra Nevada where the two species are parapatric. Two genetically based genitalic traits that differed between allopatric populations of each species formed a cline in this zone. Males captured in the field from the region of parapatry resembled offspring from interspecific laboratory hybridizations. Secondly, we surveyed electrophoretic variation of populations from across California and used $F$ statistics to estimate levels of gene flow within and between species. Results from both morphology and $F$ statistics suggested that these grasshoppers are not reproductively isolated in nature but that gene flow between species is reduced relative to within-species. These field results were consistent with a laboratory study that showed partial but not complete hybrid egg inviability. Because the hybrid zone is centred along an ecological transition, this system offers an opportunity to investigate whether adaptive changes across the zone contribute to reduced gene flow between species.
\end{abstract}

Keywords: gene flow, genitalia, grasshopper, hybrid, species.

\section{Introduction}

The biological species concept (BSC; Mayr, 1942) requires reproductive isolation between taxa before they are considered 'good' species. Despite numerous problems with this criterion (Patterson, 1985; Cracraft, 1989; Templeton, 1989), it is generally accepted as the most objective and useful for sexually reproducing animals (Coyne, 1992). Because the BSC is widely accepted, nominal species are often assumed to be reproductively isolated even in cases where this assumption has not been tested explicitly.

Tests on reproductive isolation are important. Whether two taxa exchange genes in nature may influence the genetic variation available for natural selection to act on (Lewontin \& Birch, 1966; Barton \& Bengtsson, 1.986); it may also change the relevant focus

*Correspondence. of study from community ecological questions concerning competition to both ecological and genetic questions over factors that promote or limit gene flow between populations (Barton \& Hewitt, 1985, 1989; Hewitt, 1988).

One factor complicating tests of the BSC is that morphological differences alone may not be sufficient to demonstrate that two taxa are reproductively isolated. Traits used to distinguish species may be plastic responses to different environments rather than genetically based markers of reduced gene flow (Geist, 1992). A classic example of this was phase polyphenism in locusts, which resulted in the different phases of these insects being originally classified as separate species (Uvarov, 1921). In arthropods, male genitalic differences are often used to distinguish species, yet divergence in genitalia may not physically impede copulation (Robson \& Richards, 1936; Shapiro \& Porter, 1989; Porter \& Shapiro, 1990; Eberhard, 
1993). Furthermore, male genitalia may evolve rapidly and divergently in separate populations (Eberhard, 1986). Thus genitalic differences between populations may overestimate the time that they have been apart and perhaps underestimate their potential to interbreed were they to re-establish contact.

Laboratory experiments may be used to determine whether two populations are still capable of interbreeding. However, a second difficulty in applying the BSC is that reproductive compatibility between taxa in the laboratory is by itself insufficient to show that gene flow occurs in nature. Many taxa can be artificially induced to cross and produce viable and fertile offspring in the laboratory (Bock, 1984; Coyne \& Orr, 1989 ), yet nonetheless may rarely or never mate in the field, even when sympatric (Gill, 1989; reviewed for Drosophila in Block, 1975). Hence, laboratory studies showing reproductive compatibility must be coupled with evidence of hybrid intermediates or of gene flow in the field.

This paper uses morphological and molecular techniques to infer whether two parapatric but phenotypically and ecologically distinct grasshoppers, Melanoplus sanguinipes and $M$. devastator, are reproductively isolated in nature. Grasshoppers have been especially interesting insects for studying questions of parapatry and hybridization in nature and their relation to chromosomal, morphological, and life-history traits (Hewitt, 1990; Butlin \& Ritchie, 1991; Groeters \& Shaw, 1992). The case we report on here differs from others in that one putative species virtually surrounds the other. Melanoplus sanguinipes ranges across North America and is found in California at middle to high elevations in the Sierra Nevada, along the northern coast (Gurney \& Brooks, 1959) and from Los Angeles south in habitats characterized by cooler temperatures and shorter summers. In contrast, a closely related species, $M$. devastator, is endemic to California, Washington, and Oregon. In California, $M$. devastator lives primarily in the Central Valley and along the south-central coast (Gurney \& Brooks, 1959; Strohecker et al., 1968) in habitats generally associated with long, hot, dry summers. The distributions of the two species are thought to be roughly complementary (Strohecker et al., 1968).

The differences in habitat between these grasshoppers correlate with life-history adaptations in each species. Females of $M$. devastator pass the hottest months of summer in reproductive diapause: after becoming adults in July they wait up to 3 months before producing mature eggs in the fall (Middlekauff, 1964). In contrast, $M$. sanguinipes faces relatively benign conditions at upper elevations during the summer and must complete its life cycle during a shorter growing season. Hence, populations of $M$. sanguinipes in the Sierra hatch quickly and develop rapidly (Dingle et al., 1990; M. R. Orr, unpublished data), and forego any reproductive diapause (Orr, 1994).

$M$. sanguinipes and $M$. devastator are distinguished in taxonomic keys by a larger mesosternal hump in $M$. sanguinipes (Gurney \& Brooks, 1959) and by differences in the shape of the male cercus, which is wider in M. sanguinipes (Gurney \& Brooks, 1959; Strohecker et al., 1968; Fig. 1). No other traits are used in these keys to distinguish the two species but interspecific differences in the aedeagus (Gurney \& Brooks, 1959; Strohecker, 1968) and in the shape and size of the furcula (Gurney \& Brooks, 1959) are depicted in drawings in these publications. The furcula is longer and more ornate in $M$. devastator (Gurney \& Brooks, 1959; Fig. 1).

In this study, we utilize both morphological and molecular techniques to assess gene flow between $M$. sanguinipes and $M$. devastator. Firstly, to quantify the previously qualitative and subjective classifications of individuals into morphological classes, we translate into easily measured variables some of the morphological differences between the two species. Furthermore, we treat each of the morphological traits separately as they presumably have separate genetic bases. Secondly, we ask whether interspecific differences in these measurements are genetically based and therefore indicate genetic divergence and reduced gene flow between species. Thirdly, we examine a region of parapatry between the species to test whether reproductive isolation exists. If $M$. sanguinipes and $M$. devastator are reproductively isolated, then we should expect a disjunct transition in morphological traits, with perhaps both species co-existing in some populations sympatrically. In contrast, if gene flow occurs between species, then evidence of hybrids should exist in the field. Finally, we use measurements of genetic variation at allozyme loci to quantify gene flow both within and between species.

\section{Materials and methods}

\section{Morphology}

Morphological differences. We used field-caught individuals from populations occurring well within each species range (far-allopatric) to search for simple morphological measurements that distinguished individuals of $M$. sanguinipes from $M$. devastator. Two populations of $M$. sanguinipes from high elevation in the Sierra Nevada and three populations of $M$. devastator from the Central Valley and the central coast were 

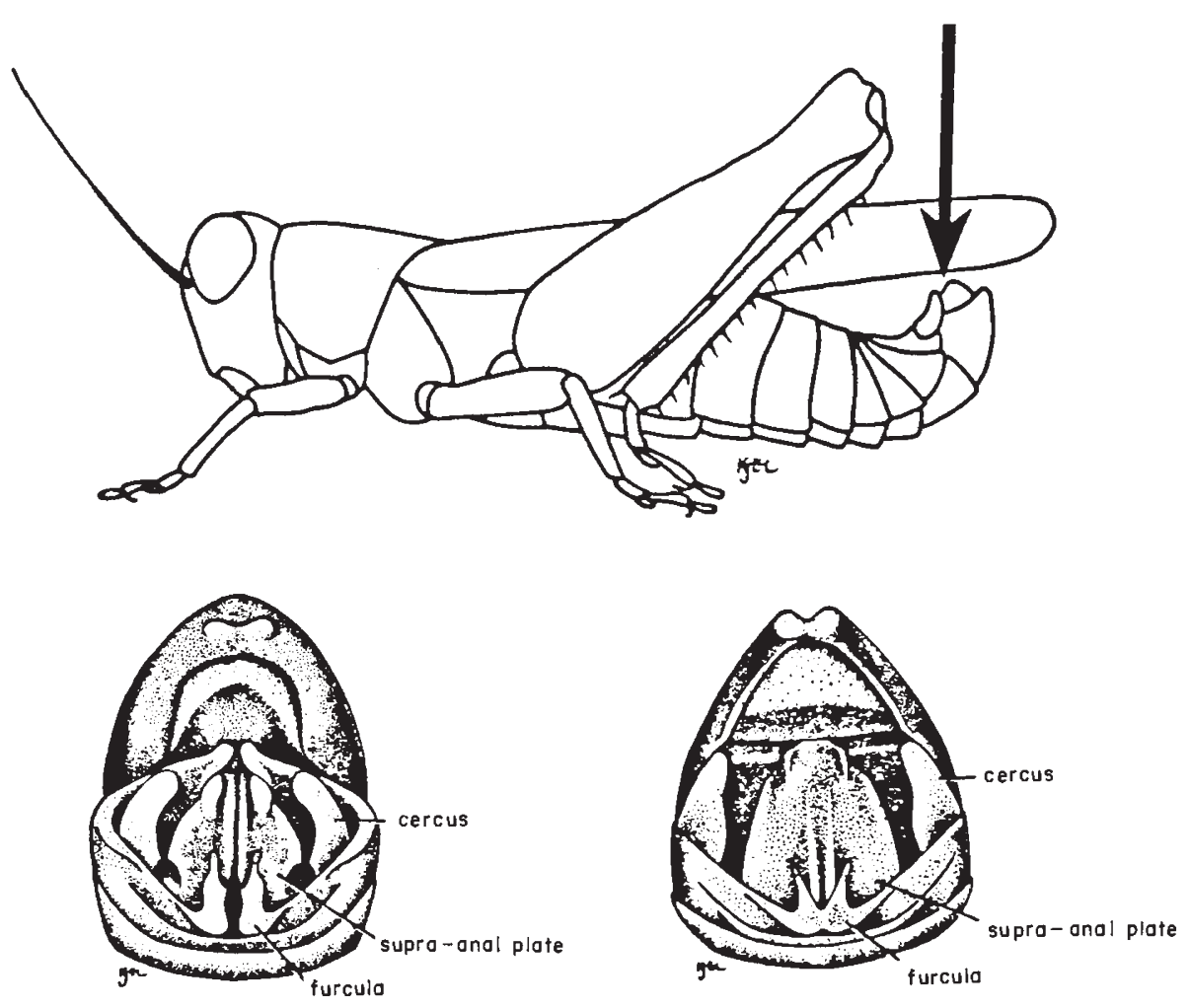

Fig. 1 Traits of $M$. sanguinipes and $M$. devastator analysed during this investigation. Arrow in drawing of complete specimen (above) marks the region depicted below left (M. devastator) and below right ( $M$. sanguinipes). Both individuals were the same body size. Note the longer and more elaborate furcula in the devastator specimen and differences in the shape of the cerci. In the $M$. devastator specimen the subgenital plate (posterior portion of abdomen) has been pulled back and downward, revealing the apical ends of the Xth tergite. The positioning of the genitalia in this $M$. devastator specimen is closer to what is seen during copulation, while that of the $M$. sanguinipes specimen is what is seen in males at rest.
Table 1 Populations and numbers of individuals used to analyse morphological differences between $M$. sanguinipes and $M$. devastator. Populations were distinguished as either $M$. sanguinipes or $M$. devastator based on geographic location

\begin{tabular}{|c|c|c|c|}
\hline Population & Location & $\begin{array}{l}\text { Field } \\
\text { caught }(n)\end{array}$ & $\begin{array}{l}\text { Laboratory } \\
\text { reared }(n)\end{array}$ \\
\hline $\begin{array}{l}\text { Leek Spring } \\
\text { (sanguinipes) }\end{array}$ & $\begin{array}{l}\text { Sierra Nevada } \\
38^{\circ} \mathrm{N} \text { latitude } \\
2150 \mathrm{~m} \text { elevation }\end{array}$ & 26 & 47 \\
\hline $\begin{array}{l}\text { Laing Road } \\
\text { (sanguinipes) }\end{array}$ & $\begin{array}{l}\text { Sierra Nevada } \\
39^{\circ} \mathrm{N} \text { latitude } \\
1500 \mathrm{~m} \text { elevation }\end{array}$ & 25 & 46 \\
\hline $\begin{array}{l}\text { Davis } \\
\text { (devastator) }\end{array}$ & $\begin{array}{l}\text { Central Valley } \\
38^{\circ} \mathrm{N} \text { latitude } \\
15 \text { m elevation }\end{array}$ & 25 & 43 \\
\hline $\begin{array}{l}\text { Santa Barbara } \\
\text { (devastator) }\end{array}$ & $\begin{array}{l}\text { southern coast } \\
35^{\circ} \mathrm{N} \text { latitude } \\
10 \mathrm{~m} \text { elevation }\end{array}$ & 21 & 20 \\
\hline $\begin{array}{l}\text { Morro Bay } \\
\text { (devastator) }\end{array}$ & $\begin{array}{l}\text { southern coast } \\
34^{\circ} \mathrm{N} \text { latitude } \\
10 \mathrm{~m} \text { elevation }\end{array}$ & 24 & 1 \\
\hline
\end{tabular}

See Table 3 and Figure 2 for locations. used in the analysis (Table 1, Fig. 2). Based on the taxonomic description and depiction of differences between species in cercus width (Strohecker et al., 1968) and furcula length (Gurney \& Brooks, 1959; see Introduction), we measured these characters for each individual. The width of the outer surface of the male cercus was measured where the concave curvature of the cercus changed from a negative to a positive slope. The furcula was measured from the posterior end of the ninth tergite to the tip of the furcula. We also measured supra-anal plate length and cercus length as 'controls' for assessing the validity of using simplified measurements to quantify the interspecific genitalic differences; based on the taxonomic keys, these latter two traits were not predicted to differ between species. To account for effects of body size on the traits, we also measured pronotum length as an indicator of body size. All measurements were made using a Wild dissecting microscope fitted with an ocular micrometer.

To determine whether any of the trait measurements were useful in quantitatively distinguishing one species from another, we performed a discriminant function analysis (DFA) using MINITAB on pronotum length and the other four character measurements. Individuals were assigned to either $M$. sanguinipes or $M$. devastator based on the geographic location of their population 


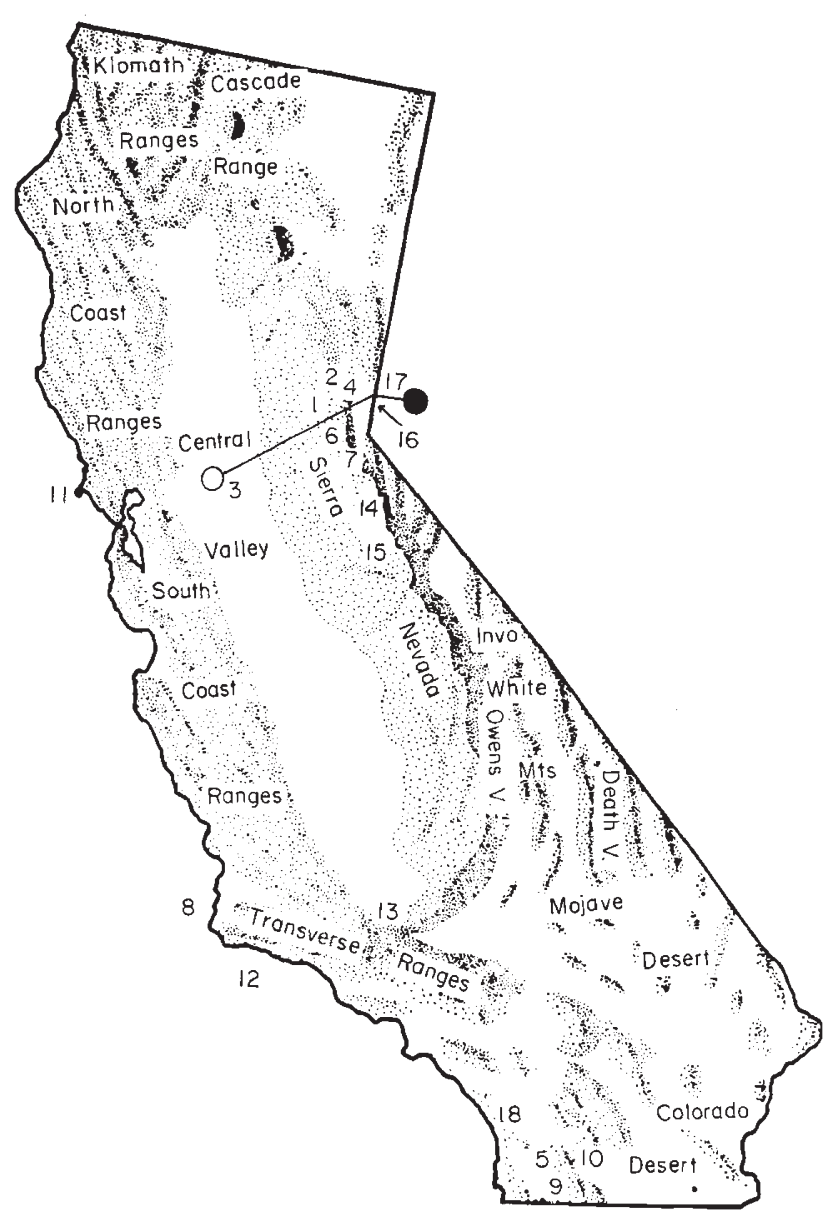

Fig. 2 Map of California, with collecting sites. Numbers correspond to populations in Table 3. The transect shown extends from Davis $(0)$ eastward over the Sierra Nevada and down the eastern slope past Reno, Nevada $(\bullet)$. Along this transect, we examined parapatric populations for evidence of hybrids in the field.

(Table 1). The DFA examined each of the measured traits separately for its accuracy in placing individuals into their correct species group (Table 2).

Tests of a genetic basis to the traits. Under common garden conditions in the laboratory, we raised offspring from the populations used in the previous experiment to determine whether traits differing between fieldcaught individuals of each species were genetically based. Egg pods laid by field caught females were placed in a cold room $\left(4^{\circ} \mathrm{C}\right) 45$ days after being laid to break embryological developmental diapause. After 120 days in the cold, eggs were removed and placed in an incubator at $25^{\circ} \mathrm{C}$. When eggs hatched, four nymphs per box were placed into $10 \times 10 \times 10 \mathrm{~cm}$ boxes with nylon screen panels and raised at $32^{\circ} \mathrm{C}, \mathrm{LD} 12: 12$ in a large walk-in incubator. Grasshoppers were rotated in racks of 20 boxes through the incubator, spending $4 \mathrm{~h}$ every other day basking under $100 \mathrm{~W}$ incandescent lights. All individuals were fed a diet of rolled oats, wheat germ and wheat bran and were given fresh romaine lettuce daily.

If field differences in morphology between the populations were to disappear under common rearing conditions in the laboratory, then such differences would be attributable to environmental rather than genetic variation. However, if field differences were maintained in the laboratory, then the remaining source of variation between populations would be genetic (Falconer, 1981).

As a second test of the genetic basis to the traits, we crossed the Laing population (high altitude $M$. sanguinipes) with the Davis population (low altitude $M$. devastator; populations 3 and 6 in Fig. 2) to examine whether any clear mode of inheritance would be demonstrated for the traits. Laboratory reared hybrids were compared with laboratory reared offspring from within-population crosses. Because genitalic traits may be influenced by body size, we analysed differences between hybrids and the two parental types using an analysis of covariance (ANCOVA) with cross type (Davis $\times$ Davis, Laing $\times$ Laing and Davis $\times$ Laing) as the classification variable and body size (pronotum length) as the covariate. Initially, the model included a term for a body size by cross type interaction, which was eliminated from the model when no significant interaction was found. The ANCOVA was run using PROC GLM on PC SAS version 6.03 (SAS Inst., Cary NC).

The hybrid crosses were part of a larger study to examine the viability and fecundity of hybrids in the laboratory. Results of that study will be mentioned in the Discussion but are available on request (M. R. Orr, unpublished data).

Reproductive isolation vs. hybridization. Our study of morphological differences between species (above) included a total of only five populations. To apply these results to a larger number of populations and to investigate how the traits changed across a known species boundary, we captured male grasshoppers in the field from 19 populations along a transect from Davis, California (elevation $15 \mathrm{~m}$ ), east along Interstate 80 through Donner Pass in the Sierra Nevada (elevation $2000 \mathrm{~m}$ ) and down the Sierra's eastern slope past Reno, Nevada (elevation 1400 m; Fig. 2). Along this transect, the species distribution maps of Gurney \& Brooks (1959) document a clear transition from populations of $M$. devastator in the Central Valley to populations of $M$. sanguinipes in the Sierra; thus we were confident that this transect crossed a zone of sympatry or parapatry. 
Table 2 Results of a discriminant function analysis using five traits to identify individuals as either $M$. sanguinipes or M. devastator

\begin{tabular}{lllll}
\hline Trait & & & & \\
\hline $\begin{array}{l}\text { Pronotum } \\
\text { length }\end{array}$ & $\begin{array}{l}\text { Cercus } \\
\text { length }\end{array}$ & $\begin{array}{l}\text { Supra-anal } \\
\text { plate }\end{array}$ & $\begin{array}{l}\text { Cercus } \\
\text { width }\end{array}$ & $\begin{array}{l}\text { Furcula } \\
\text { length }\end{array}$ \\
\hline 0.65 & 0.61 & 0.77 & 0.86 & 0.96 \\
\hline
\end{tabular}

The populations used are shown in Table 1. The number below each trait shows the proportion of individuals that were correctly classified to species using that trait. Note that the furcula and cercus best distinguished between species. The analysis was performed on 97 field-caught individuals.

Along the transect, 15-30 males were captured from each population. Pronotum length, cercus width and furcula length were measured for each individual. Hybrid morphology was determined by comparing field caught individuals to laboratory hybrids.

\section{Electrophoretic analysis}

We used an analysis of genetic variation at enzyme loci as a second independent study of gene flow within and between species. Ten to 26 grasshoppers from each of 18 populations across California (Table 3, Fig. 2) were captured and held in plastic boxes for transport back to the laboratory, where they were frozen alive at $-80^{\circ} \mathrm{C}$. Tissue was prepared for electrophoresis following the protocol of Ayala et al. (1972), modified slightly as described in Porter \& Mattoon (1989). Only adults were assayed and one hind femur was used for each tissue sample.

We examined 13 metabolic enzyme loci: adenylate kinase ( $A K$; E.C. 2.7.4.7), aldolase (ALDO; E.C. 4.1.2.13), glutamic-oxaloacetic transaminase (GOT; E.C. 2.6.1.1), alpha-glycerophosphate dehydrogenase (alpha-GPD-3; E.C. 1.1.1.8), hexokinase (two loci: $H K$ 1, HK-2; E.C. 2.7.1.1), isocitrate dehydrogenase ( $I D H$; E.C. 1.1.1.42), lactate dehydrogenase ( $L D H$; E.C. 1.1.1.27), malate dehydrogenase (two loci: $M D H-1$, $M D H-2$; E.C. 1.1.1.37), malic enzyme ( $M E$; E.C. 1.1.1.40), 6-phosphogluconate dehydrogenase (6$P G D$; E.C. 1.1.1.44) and phosphoglucose isomerase (PGI; E.C. 5.3.1.9).

The 18 populations were classified as either $M$. sanguinipes or $M$. devastator based on male furcula length, the trait found during the morphological analysis to distinguish one species from the other better than any of our other measurements. The classification of these populations using furcula length was consistent
Table 3 Description of study sites used in the allozyme analysis

\begin{tabular}{lrl}
\hline Population & & $\begin{array}{l}\text { Furcula/pronotum } \\
\text { Mean } \pm \text { s.d. }(n)\end{array}$ \\
\cline { 1 - 2 } 1. Bear Valley & 1400 & $0.191 \pm 0.014(30)$ \\
2. Damnfine Spring & 2000 & $0.167 \pm 0.016(5)$ \\
3. Davis & 15 & $0.239 \pm 0.014(25)$ \\
4. Donner & 1900 & $0.179 \pm 0.007(5)$ \\
5. Julian & 1250 & $0.184 \pm 0.009(5)$ \\
6. Laing Rd. & 1500 & $0.181 \pm 0.013(25)$ \\
7. Leek Spring & 2150 & $0.156 \pm 0.010(5)$ \\
8. Morro Bay & 10 & $0.244 \pm 0.013(24)$ \\
9. Mt. Laguna & 1300 & $0.180 \pm 0.005(5)$ \\
10. Mt. Palomar & 1950 & $0.184 \pm 0.014(5)$ \\
11. Point Reyes & 90 & $0.212 \pm 0.016(36)$ \\
12. Santa Barbara & 10 & $0.234 \pm 0.010(21)$ \\
13. Tehachapi & 1250 & $0.247(1)$ \\
14. Tioga Pass & 3300 & $0.175 \pm 0.009(5)$ \\
15. Tom's Place & 2260 & $0.168 \pm 0.014(9)$ \\
16. Truckee & 1800 & $0.160 \pm 0.011(18)$ \\
17. Verdi & 1400 & $0.165 \pm 0.011(30)$ \\
18. Whispering Palms & 100 & $0.185 \pm 0.008(4)$ \\
\hline
\end{tabular}

Numbers identify each site's geographic location in Figure 2. Furcula lengths scaled by body size were used to classify the population as either sanguinipes (below 0.195) or devastator (above 0.230); the number of individuals used to generate the genitalic size estimates is included in parentheses beside the measurement. Only one population (Point Reyes) was intermediate in furcula length; this population is located at the centre of what may be a coastal cline.

with their habitat locations: all populations classified as $M$. devastator came from low altitudes and all populations of $M$. sanguinipes except one came from high altitudes. The exception was population 18 (Table 3, Fig. 2) from southern California, where Gurney \& Brooks (1959) also found $M$. sanguinipes to occur. We used measurements of allozyme variation to construct phenograms and to estimate levels of gene flow both between populations and between species. Two populations of a wingless species of Melanoplus were used as outgroups to root the trees.

Using both Blosys (Swofford \& Selander, 1981) and our own computer program (available from Porter), we constructed the phenograms reported here: the first uses UPGMA to construct a tree from the matrix of Nei's (1978) unbiased genetic distance $(D)$; the second is a distance Wagner tree (Farris, 1972) constructed from Rogers' (1972) distances.

The electrophoretic data also were used to estimate levels of gene flow both within and between species. $F$ statistics (Wright, 1931) partition total genetic variation into hierarchical components. $F_{\mathrm{ST}}$ describes 
genetic variation among subpopulations. If $N$ is the subpopulation size and $m$ the migration rate, $\mathrm{Nm}$ represents the number of migrants per subpopulation per generation. When selection and mutation rates of the electrophoretic alleles are negligible relative to $\mathrm{Nm}$, Wright (1931) showed that $\mathrm{Nm}$ can be estimated from $F_{\mathrm{ST}}$, assuming random migration among numerous roughly equal-sized subpopulations (see also Hartl \& Clark, 1989). Slatkin \& Barton (1989) showed that estimation of $\mathrm{Nm}$ can be reliably extended to more realistic 'stepping stone' and continuous subpopulation structures.

Slatkin \& Barton (1989) showed that Weir \& Cockerham's (1984) statistical estimator of $F_{\mathrm{ST}}$ is biased and that Wright's original $F_{\mathrm{ST}}$ formulation is a better estimator, so we used Wright's $F_{\mathrm{ST}}$ for the within-species $\mathrm{Nm}$ estimates. Next, we partitioned overall genetic variation into within-species $\left(F_{\mathrm{SG}}\right)$ and between-species $\left(F_{\mathrm{GT}}\right)$ components (Porter, 1990), and used $F_{\mathrm{GT}}$ for an estimate of $\mathrm{Nm}$ between species. Porter (1990) found that $\mathrm{Nm}$ at this hierarchical level was best estimated using Weir \& Cockerham's (1984) $O_{1}$, a statistical estimator of $F_{\mathrm{GT}}$, rather than Wright's original $F_{\mathrm{ST}}$, as the value of $\mathrm{Nm}$ calculated from $F_{\mathrm{ST}}$ was two or more orders of magnitude higher than expected in controls using sympatric sibling species. We cannot yet explain why $O_{1}$ is less biased than $F_{\mathrm{ST}}$ as an estimator of gene flow between species; perhaps it is associated with the small absolute number of population groups at this hierarchical level $(n=2$ species; see Nei et al., 1977; Crow \& Aoki, 1984).

\section{Results}

\section{Morphology}

Morphological differences. The discriminant function analysis showed that our measurements of male genitalic traits were consistent with the differences between species described in the taxonomic keys. Body size, supra-anal plate length and cercus length (traits not identified as different between species in the keys) assigned individuals to the correct species group with less accuracy than either cercus width or furcula length (Table 2). Body size assigned individuals to the correct species with greater than 50 per cent accuracy because grasshoppers from the $M$. devastator populations tended to be larger than those from the $M$. sanguinipes populations. The tendency for cercus length and supraanal plate length to correctly classify more than 50 per cent of the individuals can be explained almost entirely by correlations of these traits with body size although supra-anal plate length did a slightly better job than body size alone.
The effectiveness of cercus width and furcula length in classifying individuals clearly surpassed any incidental effects of body size (Table 2; Fig. 3a). Cerci were wider in $M$. sanguinipes (as the taxonomic keys would predict). Even though $M$. sanguinipes individuals were smaller than $M$. devastator, cercus width alone correctly classified individuals 86 per cent of the time without any corrections made for body size. Furculae were longer in $M$. devastator than in $M$. sanguinipes (in accordance with the drawings in Gurney \& Brooks, 1959) and placed individuals into the correct species group 96 per cent of the time. When furcula length and cercus width were included together in the DFA, they classified all individuals in the analysis to the correct species group. We hereafter focus on these two measurements for analyses of the genetic basis of genitalia and of genitalic morphology in a region of parapatry.

Genetic basis of furcula length and cercus width. Differences between species in cercus width and furcula length were maintained in laboratory reared individuals from the five populations, suggesting that these traits have a genetic component (Fig. 3b). Although little overlap for body size between species existed in the laboratory $F_{1}$, individuals of different species that did overlap in body size shared no overlap in either furcula length or cercus width.

Genetically based genitalic differences between species were also upheld in the hybridization study of the Laing Road ( $M$. sanguinipes) and Davis ( $M$. devastator) populations. The ANCOVA analysing differences in furcula length between the Laing, Davis and Laing $\times$ Davis crosses showed no body size $\times$ cross type interaction $(F=0.88$; d.f. $=2,53 ; P=0.42)$. The effect of cross type on furcula length was highly significant $(F=72.28 ;$ d.f. $=2,55 ; P<0.0001)$. Hybrids tended to have longer furculae than offspring of pure $M$. sanguinipes crosses and shorter furculae than offspring of pure $M$. devastator crosses (Fig. 4), suggesting additive inheritance of this trait. For cercus width, there was no body size $\times$ cross type interaction $(F=0.55$; d.f. $=2,53 ; P=0.58)$ but there was a significant effect of cross type $(F=16.31$; d.f. $=2,55$; $P<0.0001)$. Unlike furcula length, however, the hybrids do not appear to be clearly intermediate between the two paternal types (Fig. 4).

Field evidence for hybridization. Along the transect across the zone of parapatry (Fig. 2), both furcula length and cercus width formed clines with coincident centres at approximately $700 \mathrm{~m}$ elevation (Fig. 5). Clines over this distance scale most often result from introgression between two 'parental' taxa (Barton \& Hewitt, 1985, 1989) and intermediate individuals at 

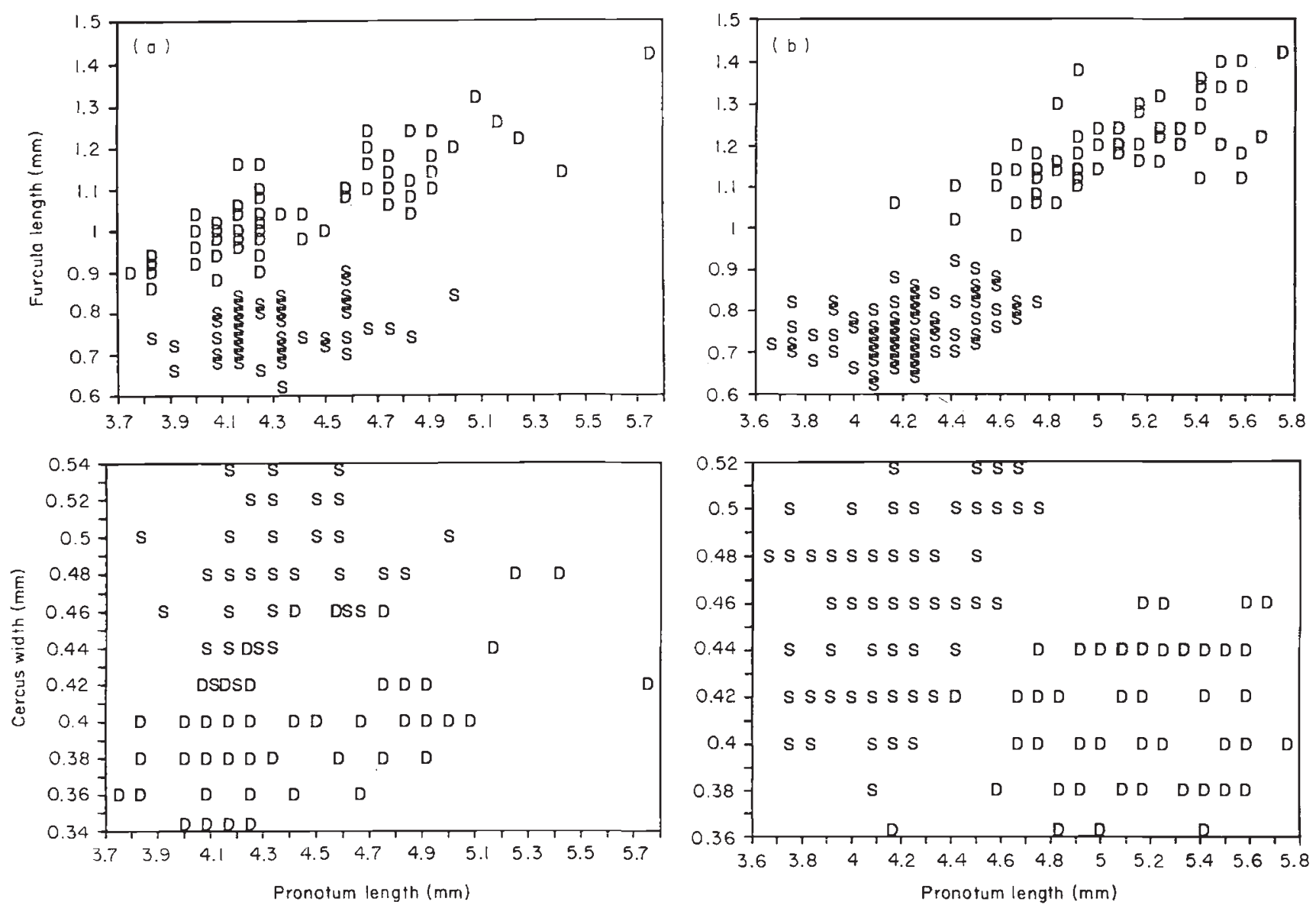

Fig. 3 (a) Furcula length vs. body size (top) and cercus width vs. body size (bottom) in field-caught individuals from five allopatric populations $(\mathrm{D}=$ M. devastator; $\mathrm{S}=M$. sanguinipes $)$. (b) Same as $(\mathrm{a})$, except grasshoppers were all raised in the laboratory. Note in (b) that interspecific differences in genitalia were maintained, suggesting a genetic basis for the trait.

the centre of the cline represent hybrids between the two parental types. The genitalic clines suggest, therefore, that gene flow exists between $M$. sanguinipes and $M$. devastator. Unless this zone marks a recent recontact, then some form of selection against hybrids may maintain the steep centre of the clines and act as a partial barrier to gene flow between taxa (Barton \& Hewitt, 1985).

The clines deserve further scrutiny, however, before reproductive isolation is rejected. Intermediate mean values for the genitalic traits in populations at the centre of the cline could occur without gene flow between species if these populations consisted of a mixture of pure $M$. sanguinipes and pure $M$. devastator living together sympatrically. Under this scenario, individuals from the centre of the cline should not be intermediate for genitalic traits but should instead show one extreme phenotype or the other.

However, individuals near the cline's centre show clearly intermediate phenotypes for furcula length (Fig.
6) that are similar to the intermediate nature of the laboratory reared hybrids (Fig. 4). The combination of a demonstrated genetic basis to the genitalic traits and the existence of hybrid individuals in the field suggests strongly that these nominal species are not reproductively isolated.

\section{Electrophoresis}

Phenograms constructed from the electrophoretic data (Fig. 7) showed that genetic distances between the species were extremely small. Comparison of these genetic distances with those of other non-Drosophila insect taxa (Thorpe, 1983) suggests that $M$. sanguinipes and $M$. devastator are differentiated around the level of subspecies or less. Note that populations of $M$. devastator are nested within the populations of $M$. sanguinipes.

Estimates of $F_{\mathrm{ST}}, F_{\mathrm{GT}}$ and $N m$ are presented in Table 4. Nm was larger within $M$. devastator than within $M$. sanguinipes which suggests that $M$. devastator has 

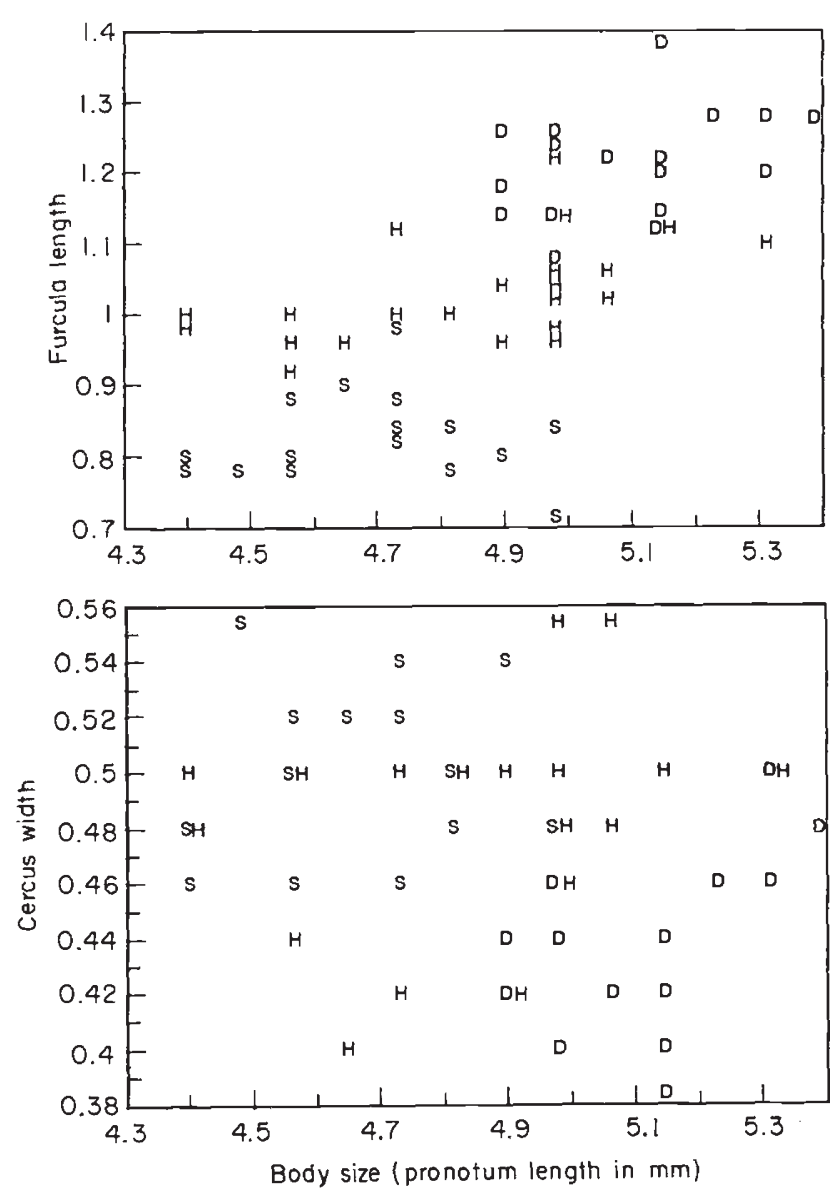

Fig. 4 Furcula length vs. body size (top) and cercus width vs. body size (bottom) for offspring of $M$. devastator from Davis, CA (D), M. sanguinipes from $1500 \mathrm{~m}$ elevation in the Sierra at Laing Road (S) and offspring of hybridizations between the species $(\mathrm{H})$. Note that genitalic differences between populations are maintained under common garden conditions and that hybrid individuals show intermediate phenotypes. The numbers of families used in each cross were $D=6$ families, $\mathrm{S}=7$ families, $\mathrm{H}=8$ families. These results suggest that there is a genetic basis to these traits.

higher migration rates. The smallest value for $\mathrm{Nm}$ occurred in the between-species comparison, supporting the inferences from the clines of reduced yet existent gene flow between species. The level of gene flow between species, one genome every four generations, is sufficient to allow these species to share mutually adaptive genes with little impediment (Barton \& Bengtsson, 1986); however, migration rates between species and within $M$. sanguinipes are at levels $(N m<0.5)$ that permit genetic drift to differentiate populations at neutral loci more rapidly than gene flow can bring them together (Wright, 1931).

\section{Discussion}

\section{Consistency between the morphological and molecular results}

Both the genitalic clines and the gene flow analysis indicated that $M$. sanguinipes and $M$. devastator were not reproductively isolated. Morphological intermediates were found in a region of parapatry in the Sierra foothills and estimates of gene flow between species were only slightly lower than estimates of gene flow between populations of $M$. sanguinipes. Furthermore, although neither of the methods supported reproductive isolation, they did indicate that gene flow between the two taxa is reduced relative to within taxa. The steep centres of the genitalic clines and the finding that $\mathrm{Nm}$ estimates were lowest between species both suggest that some barriers to gene flow exist. However, it must be emphasized that if the genitalic clines are maintained by selection, then they may not be reliable indicators of gene flow at other loci (Lande, 1982; Barton, 1983).

The findings of this study are consistent with a laboratory investigation of hybridization potential between species. An analysis of egg viability of 133 control and hybrid crosses using four populations along the cline showed that hatching rates were reduced by approximately 50 per cent in crosses between $M$. sanguinipes females and $M$. devastator males (M. R. Orr, unpublished data). The reduction in hatching rate was probably due to post-mating rather than premating isolation as it occurred even in crosses in which spermatophores were known to have been transferred. Hybrid individuals that hatched from these crosses were viable and fertile. Hence, it would appear that at least one factor inhibiting gene flow between these taxa is hybrid underdominance expressed through embryonic death. Just as with the molecular and morphological evidence, the crosses suggested that some degree of successful hybridization is possible.

Factors other than hatch failure also may limit gene flow between $M$. sanguinipes and $M$. devastator along this transect. The cline occurs along a sharp environmental gradient associated with changes in altitude. Genetic transitions in life history traits such as hatching time, development time and body size (M. R. Orr, unpublished data), as well as female reproductive diapause (Orr, 1994) occur directly across the centre of the hybrid zone. Because this life-history divergence is probably caused by seasonal differences associated with altitude, environmental selection may inhibit gene flow between high and low elevation populations. The more loci that are inhibited by selection from introgressing across the zone, the stronger will be the result- 

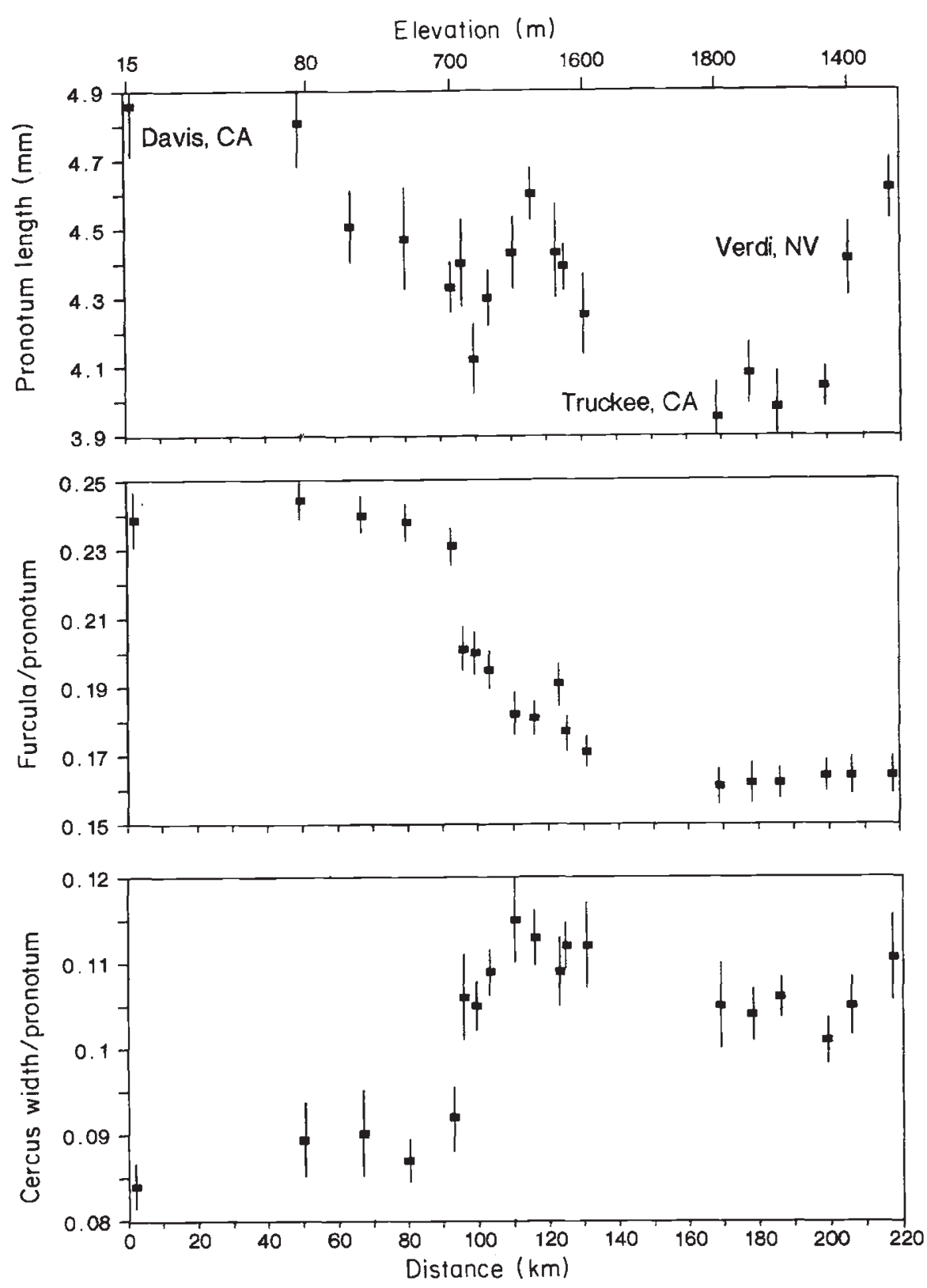

Fig. 5 Plots (mean \pm s.d.) of body size (a), furcula length divided by body size (b) and cercus length divided by body size (c) along a geographic transect from Davis ( $15 \mathrm{~m}$ elevation) eastward to the crest of the Sierra Nevada $(2000$ $m$ elevation) and down the eastern slope past Reno, NV (1400 m elevation). Note that the centres of the clines for both furcula length and cercus width coincide. Values from a single population line up vertically in this figure. ing barrier to gene flow at other neutral loci (Barton, 1983).

In addition, mate choice would appear to limit gene flow as we have found in the laboratory that homogametic matings are more common than heterogametic matings between individuals from opposite sides of the cline (M. R. Orr \& C. Sanders, unpublished data). Homogametic matings also predominated on opposite sides of a narrow hybrid zone in the European grasshopper, Chorthippus parallelus, in the Pyrenees (Butlin \& Ritchie, 1991) and likewise limited, but did not prevent, gene flow. In light of all the factors that might limit gene flow in the field, these studies are of parti- cular value because they show that hybridization and gene flow occur in nature despite these partial barriers.

\section{Are they distinct species?}

A strict interpretation of the biological species concept would require that $M$. sanguinipes and $M$. devastator no longer be considered separate species. The situation thus parallels the classic case of the subspecies C.p. parallelus and C.p. erythropus of Chorthippus parallelus also at one time considered separate species (Hewitt, 1990; Butlin \& Ritchie, 1991). One question that remains is whether the transect studied here is a 
Fig. 6 Furcula length vs. body size for individual grasshoppers from eight populations in a region of parapatry. Individuals from the same population are labelled with the same letter. Populations a- $d$ are the four populations immediately to the west of centre of the cline shown in Fig. 5b. Population a is the farthest and $d$ the closest to the cline centre. Populations $\mathrm{w}-\mathrm{z}$ are the four populations immediately to the east of cline centre, with $w$ the closest and $\mathrm{z}$ the farthest. Note that interspecific differences in furcula length are less distinct in parapatry (d vs. w) than in allopatry (a vs. z). Furthermore, individuals from the centre of the cline possess intermediate genitalic measurements similar to the offspring of interspecific crosses (Fig. 4).

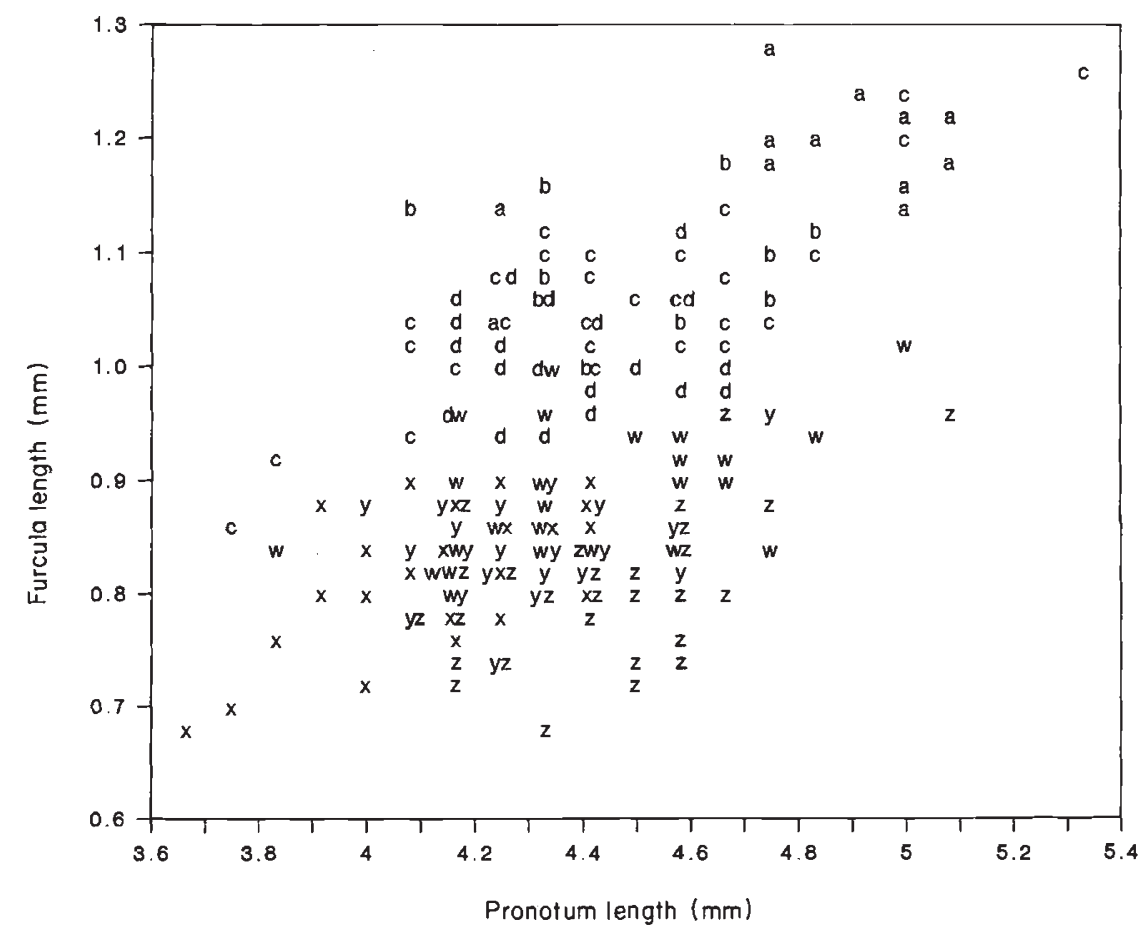

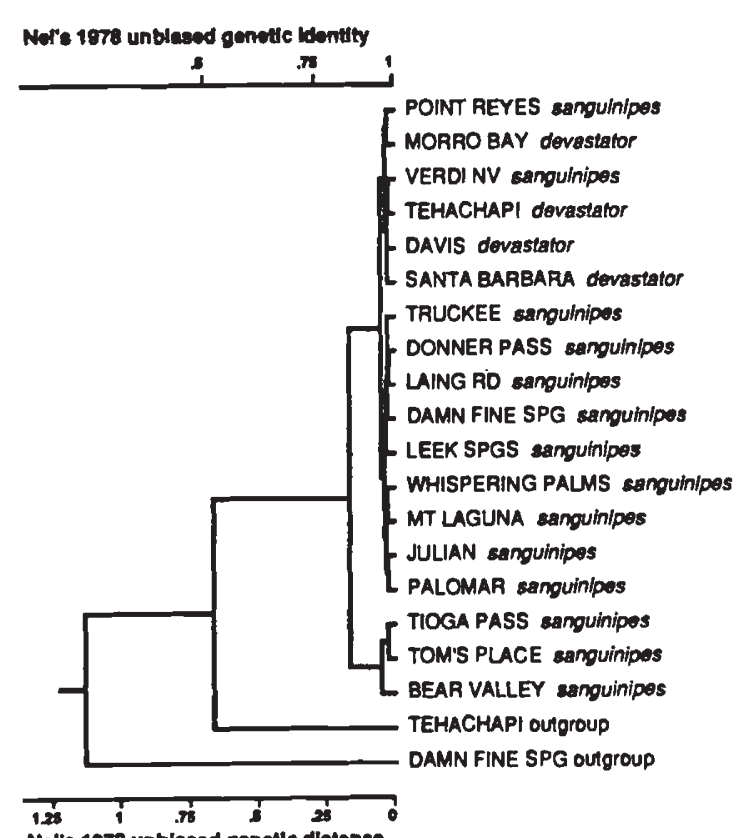

Nol': 1978 unbiased gonotic distance

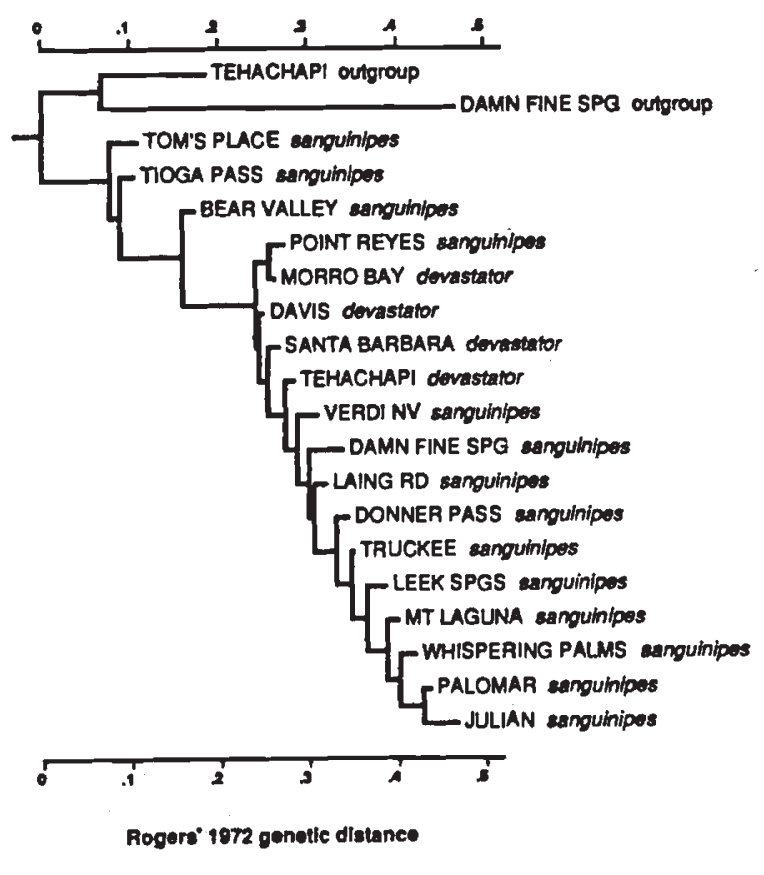

Fig. 7 Phenograms for M. sanguinipes and M. devastator. (a) Constructed using UPGMA from a matrix of Nei's (1978) unbiased genetic distance $(D)$. (b) Distance Wagner tree constructed from Rogers' (1972) distance and rooted at the midpoint of the longest path. The trees pictured here were constructed using Porter's program but were qualitatively identical using BIOsYs. Note that $M$. devastator populations cluster together but nest within $M$. sanguinipes. The Point Reyes population, which is labelled here as $M$. sanguinipes but clusters with $M$. devastator, was in fact not clearly assignable to either species on the basis of furcula length (Table 3). 
Table 4 Estimates of $F$ and $N m$ (population size $\times$ migration rate) within a species and between species

\begin{tabular}{lll}
\hline Comparison & $F$ value $( \pm$ s.d. $)$ & $N m$ (upper, lower boundaries) \\
\cline { 1 - 1 } sanguinipes & $0.449 \pm 0.053$ & $0.30(0.26,0.35)$ \\
devastator & $0.084 \pm 0.026$ & $2.72(2.08,3.85)$ \\
sanguinipes vs. & $0.503 \pm 0.054$ & $0.24(0.21,0.28)$ \\
\multicolumn{1}{c}{ devastator } & & \\
\hline
\end{tabular}

Note that the lowest estimate of migration were for the between-species comparison, suggesting reduced gene flow across taxonomic lines. The estimates of standard deviation are derived from jackknifing over loci, as recommended by Weir and Cockerham (1984). The upper and lower boundaries of $\mathrm{Nm}$ are derived from the 95 per cent confidence interval of the corresponding $F$ value.

single rare zone of contact and gene flow, or whether introgression between $M$. sanguinipes and $M$. devastator is common in other regions. Even if this hybrid zone were the only site of introgression between the taxa, it represents a genetic corridor for gene flow to carry genetically favourable traits between the taxa. It follows that the evolutionary histories of these taxa are linked although selection maintains differences on either side.

Knowing that the nominal species status of $M$. sanguinipes and $M$. devastator does not mean that they are isolated reproductively should influence the approach taken to understand their ecology and evolution. Future studies of this system might now include not only an ecological focus on adaptation to climate at different latitudes and altitudes but also a population genetic focus on whether ecological divergence influences gene flow between populations. With this approach in mind, we have begun by investigating whether and how adaptive life-history traits change across the centre of this hybrid zone (above). Because of the numerous adaptive changes that occur across the zone, $M$. sanguinipes and $M$. devastator might be considered different species under the cohesion concept of a species: adaptive differences reduce the 'demographic exchangeability' of one species by the other Templeton (1989).

Regions of parapatry along the coast may provide further insight into the relationship between adaptation and reproductive isolation in this system. The distribution maps of Gurney \& Brooks (1959) suggest potential zones of contact between $M$. devastator and $M$. sanguinipes along both the central and southern coast. Coastal hybrid zones might offer an opportunity to compare transitions in adaptive traits along the gradual environmental gradient on the coast to adaptive transitions along the steeper climatic gradient in the Sierra. A comparison between a coastal and montane hybrid zone of gene flow, genitalic cline steepness, life-history transitions and hybrid viability might further elucidate the role that environmental selection and adaptation has played in causing divergence and reduced gene flow between these taxa.

\section{Acknowledgements}

We thank Mitch Baker, Stuart Barker, Scott Carroll, Chuck Fox, Laurie McLennan and Tim Prout for input that greatly improved the manuscript. Jim Dykes was statistically significant as a consultant. Brad Shaffer and Rob Page generously lent us their resources for electrophoresis. Kim Waddell helped collect grasshoppers, and Jon Dunn, Beth Moorman, Kim Moraes, Janice Wang and Augie Lung helped with rearing. This research was supported by Grant 8806049 from the U.S. National Science Foundation and a UCD faculty enhancement award to $\mathrm{H}$. Dingle; postdoctoral fellowships from the Natural Sciences and Engineering Research Council of Canada to T. A. Mousseau; and a UC Davis Center for Population Biology Grant and a Jastro Shields Graduate Research Scholarship to M. R. Orr.

\section{References}

AYAlA, F. J., POWELL, J. R., TRACEY, M. L. AND PEREZ-SALAS, S. 1972. Enzyme variability in the Drosphila willistoni group. IV. Genetic variation in natural populations of Drosophila willistoni. Genetics, 70, 113-139.

BARTON, N. H. 1983. Multilocus clines. Evolution, 37, 454-471.

BARTON, N. H. AND BENGTSSON, B. O. 1986. The barrier to genetic exchange between hybridizing populations. Heredity, 57, 357-376.

BARTON, N. H. AND HEWITT, G. M. 1985. Analysis of hybrid zones. Ann. Rev. Ecol. Syst., 16, 113-148. 
BARTON, N. H. AND HEWITT, G. M. 1989. Adaptation, speciation and hybrid zones. Nature, 34 1, 497-503.

BLOCK, K. 1975. Chromosomal variation in Agromyzidae (Diptera). IV. Further observations on natural hybridization between two semispecies within Phytomyza abdominalis. Hereditas, 79, 199-208.

BOCK, I. R. 1984. Interspecific hybridization in the genus Drosophila. Evol. Biol., 18, 41-70.

BUTLIN, R. K. AND RITCHIE, M. G. 1991. Variation in female mate preference across a grasshopper hybrid zone. J. Evol. Biol., 4, 227-240.

COYNE, J. A. 1992. Genetics and speciation. Nature, 355, 511-515.

COYNE, J. A. AND ORR, H. A. 1989. Patterns of speciation in Drosophila. Evolution, 43, 362-381.

CRACRAFT, J. 1989. Speciation and its ontology: the empirical consequences of alternative species concepts for understanding patterns and processes of differentiation. In: Otte, D. and Endler, J. A. (eds) Speciation and Its Consequences. Sinauer Associates, Sunderland, MA.

CROW, J. F. AND AOKI, K. 1984. Group selection for a polygenic behavioral trait: estimating the degree of population subdivision. Proc. Natl. Acad. Sci. USA, 81, 6073-6077.

DINGLE, H., MOUSSEAU, T. A. AND SCOTT, S. M. 1990. Altitudinal variation in life cycle syndromes of California populations of the grasshopper, Melanoplus sanguinipes. Oecologia, 84, 199-206.

EBERhARD, w. G. 1986. Sexual Selection and Animal Genitalia. Harvard University Press, Cambridge, Mass.

EBERHARD, w. G. 1993. Species isolation, genital mechanics and the evolution of species-specific genitalia in three species of Macrodactylus beetles (Coleoptera, Scarabeidae, Melolonthinae). Evolution, 46, 1774-1783.

FALCONER, D. S. 1981. Introduction to Quantitative Genetics, 2nd edn. John Wiley, New York.

FARRIS, J. S. 1972. Estimating phylogenetic trees from distance data. Am. Nat., 106,645-668.

GEIST, v. 1992. Endangered species and the law. Nature, 357, 274-276.

GILL, D. E. 1989. Fruiting failure, pollinator inefficiency, and speciation in orchids. In: Otte, D. and Endler, J. A. (eds) Speciation and Its Consequences. Sinauer Associates, Sunderland, MA.

GROETERS, F. R. AND SHAW, D. D. 1992. Association between latitudinal variation in embryonic development time and chromosome structure in the grasshopper Caledia captiva (Orthoptera: Acrididae). Evolution, 46, 245-257.

GURNEY, A. B. AND BRoOKS, A. R. 1959. Grasshoppers of the Mexicanus group, genus Melanoplus (Orthoptera: Acrididae). Proceedings of the United States National Museum, 110, 1-93.

HARTL, D. L. AND ClARK, A. G. 1989. Principles of Population Genetics, 2nd edn. Sinauer Associates, Sunderland, MA.

HEWITT, G. M. 1988. Hybrid zones - natural laboratories for evolutionary studies. Trends Ecol. Evol., 3, 158-167.

HEWITT, G. M. 1990. Divergence and speciation as viewed from an insect hybrid zone. Can. J. Zool., 68, 1701-1715.

LANDE, R. 1982. Rapid origin of sexual isolation and character divergence in a cline. Evolution, 36, 213-223.
LEWONTIN, R. C. AND BIRCH, L. C. 1966. Hybridization as a source of variation for adaptation to new environments. Evolution, 20, 315-336.

MAYr, E. 1942. Systematics and the Origin of Species. Columbia University Press, New York.

MIDDLEKAUFF, w. W. 1964. Effects of photoperiod upon oogenesis in Melanoplus devastator. J. Kans. Entomol. Soc., 37, 163-168.

NEI, M. 1978. Estimation of average heterozygosity and genetic distance from a small number of individuals. Genetics, 89, 583-590.

NEI, M., Chakravarti, A. AND TATENo, Y. 1977. Mean and variance of $F_{\mathrm{ST}}$ in a finite number of incompletely isolated populations. Theor. Pop. Biol., 11, 291-306.

ORR, M. R. 1994. Geographic variation, life history adaptation and reproductive isolation in two California grasshoppers (Melanoplus sanguinipes and M. devastator). Ph.D Thesis, University of California, Davis.

PATTERSON, H. E. H. 1985. The recognition concept of species. In: Vrba, E. S. (ed.) Species and Speciation, Transvaal Museum Monograph No. 4, Pretoria, pp. 21-29.

PORTER, A. H. 1990. Testing nominal species boundaries using gene flow statistics: the taxonomy of two hybridizing admiral butterflies (Limenitis: Nymphalidae). Syst. Zool., 39, 131-148.

PORTER, A. H. AND SHAPIRO, A. M. 1990. Lock-and-key hypothesis: lack of mechanical isolation in a butterfly (Lepidoptera: Pieridae) hybrid zone. Ann. Entomol. Soc. Am., 83, 107-114.

PORTER, A. H. AND MATTOON, S. O. 1989. A new subspecies of Coenonympha tullia (Muller) (Nymphalidae: Satyrinae) confined to the coastal dunes of northern California. $J$. Lepidopt. Soc., 43, 229-238.

ROBSON, G. C. AND RICHARDS, o. w. 1936. The Variation of Animals in Nature. Longmans, London.

ROGERS, J. S. 1972. Measures of genetic similarity and genetic distance. Studies in Genetics. VII. University of Texas Publication 7213, pp. 145-153.

SHAPIRO, A. M. AND PORTER, A. H. 1989. The lock-and-key hypothesis: evolutionary and biosystematic interpretation of insect genitalia. Ann. Rev. Entomol., 34, 231-245.

SLATKIN, M. AND BARTON, N. H. 1989. A comparison of three indirect methods for estimating average levels of gene flow. Evolution, 43, 1349-1368.

STROHECKER, H. F., MIDDLEKAUFF, W. W. AND RENTZ, D. C. 1968. The Grasshoppers of California (Orthoptera: Acrididae). University of California Press, Berkeley.

SWOFFORD, D. L. AND SELANDER, R. B. 1981. BIOSYS 1: a FORTRAN program for the comprehensive analysis of electrophoretic data in population genetics and systematics. J. Hered., 72, 281-283.

TEMPLETON, A. R. 1989. The meaning of species and speciation: a genetic perspective. In: Otte, D. and Endler, J. A. (eds), Speciation and Its Consequences, Sinauer Associates, Sunderland, MA.

THORPE, J. P. 1983. Enzyme variation, genetic distance and evolutionary divergence in relation to levels of taxonomic separation. In: Oxford, G. S. and Rollinson, D. (eds), 
Protein Polymorphisms: Adaptive and Taxonomic Significance, Academic Press, New York.

UVAROV, B. P. 1921. A revision of the genus Locusta, L., with a

new theory as to the periodicity and migrations of locusts.

Bull. Ent. Res., 12, 135-163.
WEIR, B. S. AND COCKERHAM, C. C. 1984. Estimating F-statistics for the analysis of population structure. Evolution, 38, 1358-1370.

WRIGHT, s. 1931. Evolution in Mendelian populations. Genetics, 16, 97-159. 